\title{
Medicações sistêmicas e queixa ocular: Alguma correlação?
}

A

o ser convidado para escrever este editorial, pensei em um tema diferente, que pudesse oferecer alguma contribuição ao leitor. Refiro-me aos possíveis efeitos colaterais oculares associados com medicações sistêmicas, comumente utilizadas por nossos pacientes. Estaria cada oftalmologista ciente que drogas familiares e tradicionalmente não apontadas como tóxicas ao olho, podem estar associadas com a queixa principal de uma avaliação ocular?

Recentemente, examinei um jovem com 26 anos de idade e dificuldade de adaptação ao escuro, notada pela primeira vez e há poucas semanas. Com um histórico familiar negativo, perfil psicológico e exame oftalmológico normais, estava diante de um caso atípico de distrofia ou simulação. Durante questionário informal sobre a existência, ou não, de alguma medicação, me interessei mais pela droga acutane (isotretinoina), a única que o paciente utilizava nas últimas semanas para acne cutânea. Confesso que meu conhecimento sobre a droga acutane se limitava ao seu potencial efeito tóxico ocular quando utilizado localmente, sob forma de loção (ceratoconjuntivite). Aprendi que seu uso sistêmico pode interferir com o metabolismo da vitamina A e causar danos visuais funcionais do tipo demonstrado por este paciente $^{(1)}$. Também aprendi que já foram descritos casos semelhantes e outros com meibomite, discromatopsia e redução visual permanente associado ao uso desta medicação (1-2). A isotretinoina reduz a atividade da dehidrogenase 11-cis-retinol, prejudicando a regeneração da rodopsina no ciclo visual. Por atuar na transcrição do DNA, reduz eficazmente a secreção de glândulas sebáceas, motivo principal de sua indicação para acne ${ }^{(1-2)}$. Após suspenção da medicação e desaparecimento do sintoma, ficou mais evidente o papel iatrogênico do acutane sistêmico neste caso. Para minha surpresa, experiência semelhante associada com o uso de acutane sistêmico acaba de ser relatada na revista Retina ${ }^{(3)}$ em um paciente portador de distrofia retiniana prévia. Não pretendo com este editorial, sob forma de apresentação de um raro e único caso, comprometer a indicação correta desta medicação, já consagrada entre os melhores tratamentos para acne, há mais de 20 anos no mercado ${ }^{(4)}$. Pretendo, sim, alertar aos colegas oftalmologistas sobre os efeitos "concomitantes e silen- 
ciosos" que medicações sistêmicas familiares exercem no globo ocular humano. O mesmo tem ocorrido com diuréticos, anti-hipertensivos, hipoglicemiantes, antidepressivos e inibidores da fosfodiesterase (Viagra), medicações rotineiras e comumente desacreditadas com relação a possíveis efeitos oculares adversos. A manifestação clínica destes efeitos poderá, ou não, ser desvendada pelo paciente ou pelo próprio médico.

Eduardo Cunha de Souza

Doutor em Oftalmologia pela Universidade de São Paulo UNIFESP - São Paulo (SP) - Brasil

\section{REFERÊNCIAS}

1. Fraunfelder FW. Ocular side effects associated with isotretinoin. Drugs Today (Barc). 2004;40(1):23-7. Review.

2. Fraunfelder FT, Fraunfelder FW, Edwards R. Ocular side effects possibly associated with isotretinoin usage.Am J Ophthalmol. 2001;132(3):299-305.

3. Sanchez-Chicharro D, Pastor JC, Galvez MI, Martin RM, Asensio RC, Spirn M, et al. Diagnostic and therapeutic challenges. Retina. 2008;28(1):174-179.

4. Katsambas A, Dessinioti C. New and emerging treatments in dermatology: acne. Dermatol Ther. 2008; 21(2):86-95. 